\title{
The Application of Electrical Impedance Tomography During the Ventilator Weaning Process
}

\section{Guan Wang \\ Lei Zhang \\ Bin Li \\ Bingyin Niu \\ Jian Jiang \\ Duo Li \\ Zhu Yue \\ Yibing Weng}

Department of Critical Care, Beijing Luhe Hospital, Capital Medical University,

Beijing, People's Republic of China
Correspondence: Yibing Weng

Department of Critical Care, Beijing Luhe

Hospital, Capital Medical University,

Beijing, People's Republic of China

Tel +86 I06954390I-2I 28

Email yibingweng@ccmu.edu.cn
Background: This study proposes the investigation of electrical impedance tomography (EIT) as a useful predictor for ventilator weaning.

Methods: The study design was a nested case-control study and patients who were admitted to the intensive care unit and underwent their first tracheal intubation were enrolled. Those who successfully completed ventilator weaning and extubation after the first spontaneous breathing trial (SBT) were included in the weaning success group, while those who did not pass the SBT or received secondary intubation within 48 hours were included in the weaning failure group. In both groups, EIT was adopted to record the monitoring data in three phases: before the SBT (pre-SBT), during the SBT (SBT), and after the SBT (post-SBT).

Results: A total of 53 patients were enrolled, including 41 cases in the weaning success group and 12 cases in the weaning failure group. The logistic regression analysis showed that the pre-SBT global impedance (GI) and the SBT region of interest 2 (ROI2) were significantly higher in the weaning success group than in the weaning failure group $(p=0.0001$ and $\mathrm{p}=0.002$ ). The pre-SBT GI predicted weaning success with a sensitivity of 0.524 , a specificity of 0.818 , a p-value of 0.0496 , and a $95 \%$ confidence interval (CI) of $0.001-$ 0.978. The sensitivity, specificity, p-value, and 95\% CI for the SBT ROI2 were 1, 0.595, 0.0164 , and 1.010-1.108, respectively.

Conclusion: For patients without contraindications to EIT, the application of EIT is recommended to be added to the existing evaluation system for ventilator weaning, as it could help improve the weaning success rate. Further cohort studies are needed to investigate the actual efficacy of EIT after it has been added to the evaluation system.

Keywords: electrical impedance tomography, mechanical ventilation, ventilator weaning, prediction

\section{Background}

Since the introduction of invasive mechanical ventilation in clinical practice, the question of when to conduct ventilator weaning and the rate of weaning success have been important issues in the field of intensive care. Clinical practitioners have worked tirelessly to establish a clinical evaluation system to help select the timing and predict the success of ventilator weaning. This system mainly includes the screening of patients pre-weaning together with the use of evaluation indicators at the time of ventilator weaning. Using this evaluation system, approximately 75 $80 \%$ of patients complete the one-time ventilator weaning and extubation process, while the remaining $20-25 \%$ fail to be weaned. ${ }^{1,2}$ The exact causes of failed ventilator weaning are still debatable, but recent studies have shown that $60 \%$ of such cases could be avoided. ${ }^{3-6}$ This suggests that the current evaluation system 
needs to be improved by introducing new indicators, especially those that reflect patients' pulmonary ventilation dynamics before and after ventilator weaning.

Electrical impedance tomography (EIT) is a technique developed in recent years, which is based on the emission of impedance waves from 16 electrodes tied to defined sites in the thorax (generally between the fourth and sixth ribs for a positive body type [The body is well-proportioned, and the upper abdominal Angle is equal to $90^{\circ} \mathrm{J}$ ). It calculates the attenuation of impedance waves between different tissues in the thorax and adopts the corresponding algorithm to reduce it to a tomographic image of the pulmonary tissue. The impedance wave emitted by the EIT electrodes is inconsistently attenuated in different tissue forms, resulting in a high impedance value in well-ventilated areas, a decreased value in less-ventilated areas, and a baseline impedance value (the minimum) in unventilated areas. It is similar to conventional computed tomography, but the difference is that EIT is continuous and dynamic, reflecting changes in the pulmonary tissue during inspiration and expiration in real time through the monitoring screen. It can also be used to precisely evaluate the ventilation status of a specific area of the tissue through the device's localized monitoring function, thus helping clinical staff determine whether a patient is in a pathological state or exhibiting a degree of recovery from a disease. ${ }^{7-13}$ In preliminary observations of ventilator weaning under EIT monitoring, we have found that a proportion of patients who meet the criteria for ventilator weaning according to the traditional evaluation system show poor inspiratory and expiratory imaging of the lungs when EIT is applied, ie, significantly smaller impedance values and decreased blood oxygen and respiratory muscle fatigue during the continuation of the spontaneous breathing trial (SBT). However, in other patients who do not fully meet the predictors for ventilator weaning, the EIT imaging suggests good ventilation of the lungs and continues to be stable after extubation. Therefore, the present study evaluates whether EIT could help predict ventilator weaning in patients undergoing invasive mechanical ventilation.

\section{Methods}

\section{Study Design}

The present study was a nested case-control study conducted at the Beijing Luhe Hospital, Capital Medical University, Beijing, China. Patients admitted to the Department of Intensive Care Medicine and who underwent tracheal intubation for invasive mechanical ventilation between December 1, 2017, and September 30, 2018, were enrolled. Those who successfully completed ventilator weaning and extubation after the first SBT were included in the weaning success group, while those who failed to pass the SBT or received secondary intubation within 48 hours following extubation were included in the weaning failure group. The present study was approved by the hospital's ethics committee, with the approval number 2018LH-KS-015 and the clinical trial registration number ChiCTR1800015680.

\section{The Inclusion and Exclusion Criteria}

The inclusion criteria were as follows: patients who were intubated for the first time and who were expected to be intubated for at least 72 hours. The exclusion criteria were as follows: patients with a body mass index (BMI) $>35 \mathrm{~kg} /$ $\mathrm{m}^{2}$, patients with cardiac pacemakers or implanted electronic devices, patients undergoing spinal surgery, patients with confirmed neurogenic ventilator dependency or anticipated tracheotomy, patients with moderate to severe acute respiratory distress syndrome, and patients who were pregnant.

\section{SBT Methods}

The pre-weaning SBT screening followed the protocol set out in the "Guidelines for Mechanical Ventilation Withdrawal in Critically Ill Patients," 14 jointly issued by the American Thoracic Society and American College of Chest Physicians. Here, t-tube and ventilator weaning with a tube were adopted in the SBT, with complete aspiration and disconnection of the ventilator from the T-tube before weaning. The oxygen flow rate was $6 \mathrm{~L} / \mathrm{min}$, and the duration of weaning was three minutes. If there was no noticeable change in a patient's vital signs and oxygenation, ventilator weaning was continued for 30 minutes. The tracheal tube was extubated when the arterial blood gas (ABG) oxygenation index decreased by no more than $30 \%$ compared with pre-weaning values. Following extubation, oxygen inhalation with an oxygen flow rate of $6-8 \mathrm{~L} / \mathrm{min}$ was administered.

The SBT was repeated in the weaning failure group after elective evaluation until extubation. Those who underwent the $\mathrm{SBT} \geq 3$ times were excluded from the study. The body position of the patients was maintained at a 30-degree head elevation during the SBT. 


\section{Data Collection}

EIT was adopted to record all impedance data before the SBT (pre-SBT), during the SBT (SBT), and after the SBT (post-SBT) in both groups. Details on the patients' demographic characteristics; primary diagnosis; main diagnosis on admission to the intensive care unit; $\mathrm{ABG}$ at 30 minutes pre-SBT; ABG at 30 minutes after extubation; levels of hemoglobin, platelets, and leukocytes; and blood biochemistry were collected in both groups.

\section{EIT Data Analysis}

EIT imaging was divided into four regions of interest (ROI) in the horizontal mode: ROI1, ROI2, ROI3, and ROI4. The sum of the ROI impedance values was taken as the global impedance (GI). MATLAB 7.2 software (The MathWorks Inc., Natick, MA, USA) was used to design a processing program to analyze the four ROIs and the impedance values reflected by the GI (Figure 1).

\section{Statistical Processing}

SAS 9.4 software (SAS Institute Inc., Cary, NC, USA) was employed for the statistical analysis. Countable variables, such as gender, were expressed as categorical data. Measured data, such as age, height, weight, BMI, and impedance values, were expressed as the mean \pm standard deviation $(\overline{\mathrm{x}} \pm \mathrm{s})$. The Kruskal-Wallis test was used for non-normally distributed data. Logistic regression was used to screen for factors associated with ventilator weaning success, such as the impedance values, demographic characteristics, and blood biochemical indicators. A $p$-value $<0.05$ was considered statistically significant for all tests.

\section{Results}

\section{General Characteristics}

Fifty-three patients were included in the study: 41 in the weaning success group and 12 in the weaning failure group. There were no statistical differences in the demographic characteristics, duration of mechanical ventilation, or days of admission between the two groups (Table 1, Figure 2).

\section{Screening of the Positive Factors by} Logistic Regression Analysis During the First Ventilator Weaning Process in the Weaning Success Group and the Weaning Failure Group

\section{EIT Positive Factors}

The pre-SBT GI was significantly higher in the weaning success group than in the weaning failure group $(327,179.69 \pm 225,318.54$ versus $286,800 \pm 147,891$, respectively; $\left.\chi^{2}=14.7321 ; p=0.0001\right)$. Similarly, the

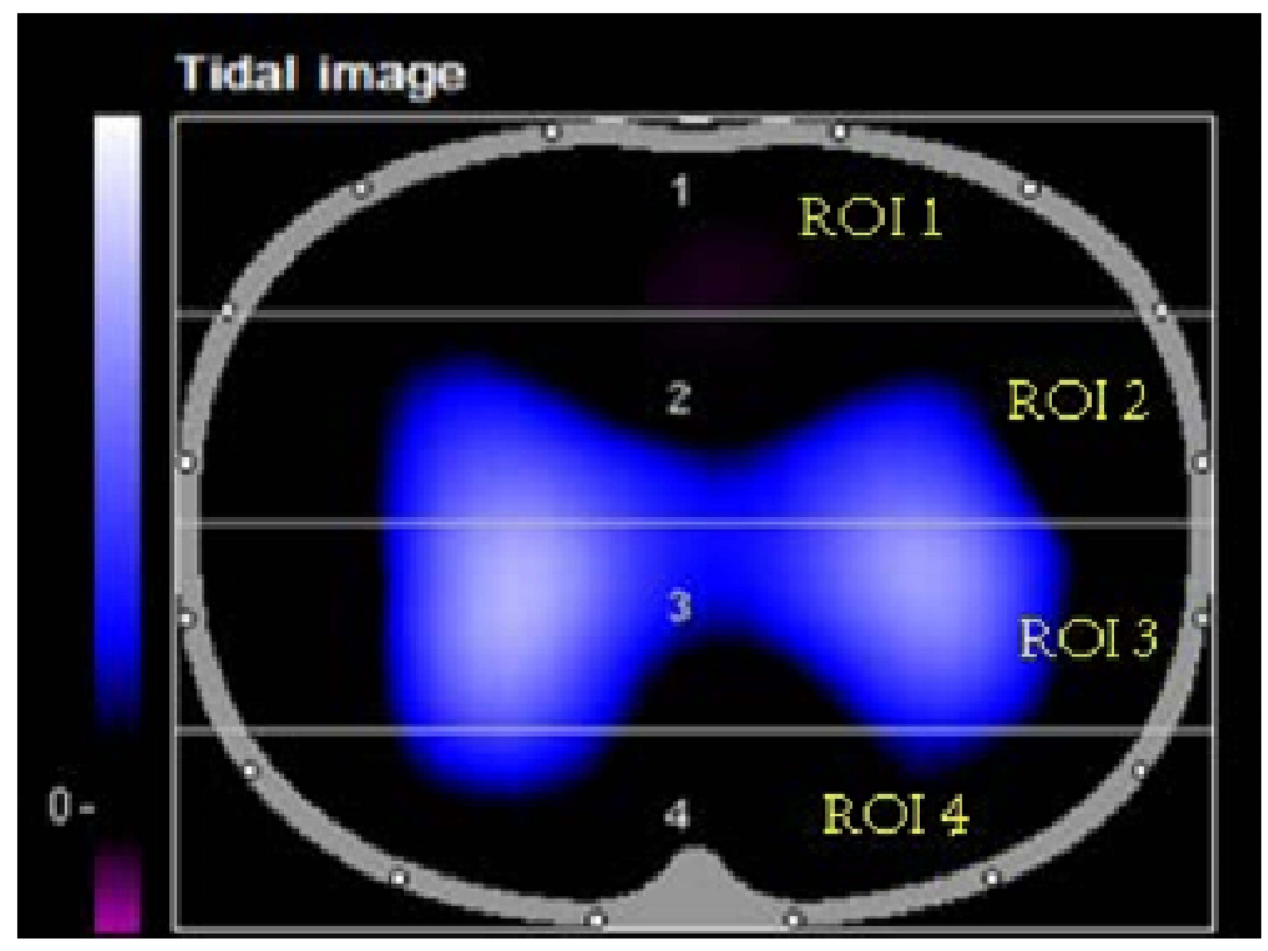

Figure I Schematic diagram of EIT dynamic image horizontal distribution (ROI = region of interest). 
Table I Patients Characteristic (Total Cases $n=53$ )

\begin{tabular}{|c|c|c|c|c|}
\hline & $\overline{\mathrm{x}} \pm \mathrm{s}$ & Experimental Group $n=41$ & Control Group $n=12$ & $p$ value \\
\hline \multicolumn{5}{|l|}{ Patient characteristics } \\
\hline Age (Years) & $62 \pm 12$ & $61 \pm 16$ & $59 \pm 19$ & 0.885 \\
\hline Weight $(\mathrm{Kg})$ & $67.1 \pm 13.6$ & $66.8 \pm 13.3$ & $68.3 \pm 15.4$ & 0.753 \\
\hline Height $(m)$ & $1.66 \pm 0.10$ & $1.66 \pm 0.09$ & $1.68 \pm 0.10$ & 0.640 \\
\hline BMI & $23.5 \pm 4.5$ & $23.4 \pm 4.8$ & $24.0 \pm 2.8$ & 0.693 \\
\hline Duration of MV (day) & $7 \pm 4$ & $6 \pm 4$ & $5 \pm 4$ & 0.237 \\
\hline Gender (M: F) & $33: 20$ & $28: 13$ & $7: 5$ & 0.412 \\
\hline \multicolumn{5}{|l|}{ Diagnosis n (\%) } \\
\hline Cardiosurgery & & $8(19)$ & $4(33.3)$ & l \\
\hline Chest surgery & & $2(4.8)$ & l & l \\
\hline Gastrointestinal surgery & & $17(40.5)$ & $4(33.3)$ & l \\
\hline Cardiovascular diseases & & $5(11.9)$ & $2(16.7)$ & l \\
\hline Urinary surgery & & $2(4.8)$ & l & l \\
\hline Trauma & & $3(7.1)$ & l & l \\
\hline Pneumonia & & $5(11.9)$ & $2(16.7)$ & l \\
\hline
\end{tabular}

SBT ROI2 was significantly higher in the weaning success group than in the weaning failure group $(316,615 \pm$ 521,982 versus $237,090 \pm 197,280$, respectively; $\chi^{2}=$ 9.5871; $p=0.002<0.01$ ) (Table 2, Figure 3).

\section{Other Factors}

In the weaning success group, the pre-SBT $\mathrm{pH}$, bicarbonate, and hemoglobin values, and the post-SBT arterial $\mathrm{pH}$ and $\mathrm{CO}_{2}$ partial pressure $\left(\mathrm{PCO}_{2}\right)$ were all better than those in the weaning failure group $(p<0.0001)$. However, the results of arterial blood lactate and serum alanine aminotransferase (ALT) analysis suggest that the weaning success group is not better than the weaning failure group $(p<0.0001)$ (Table 3$)$.

Specificity and Sensitivity of Pre-SBT GI and SBT ROI2 in Predicting Weaning Success

In EIT, the most important indicators for predicting ventilator weaning success are the pre-SBT GI and the SBT

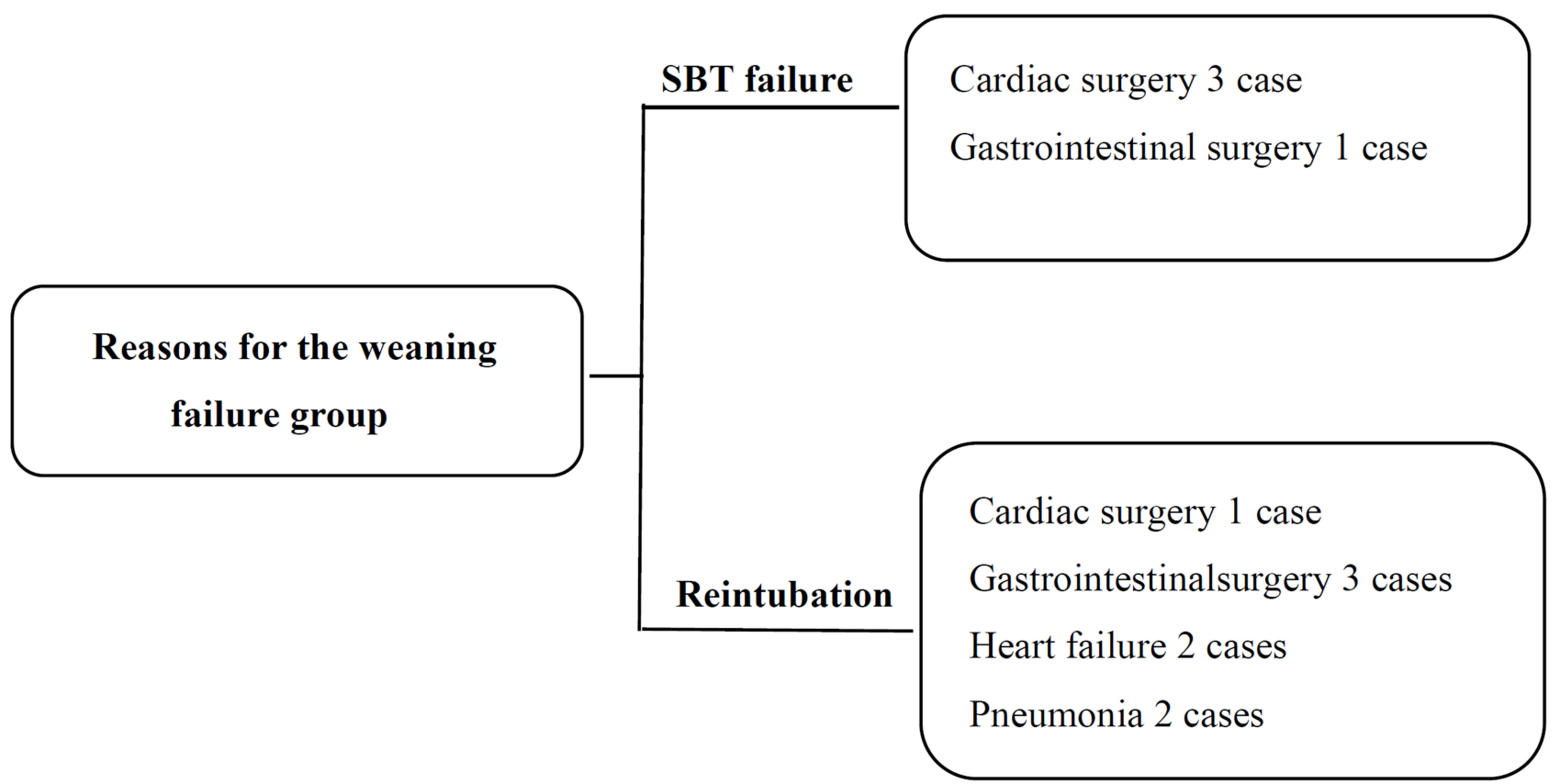

Figure 2 Reasons for weaning failure in the weaning failure group. 
Table 2 Screening of Positive Factors During Weaning in the Weaning Success and Weaning Failure Group

\begin{tabular}{|l|c|c|c|c|}
\hline Effect & $\overline{\mathrm{x}} \pm \mathrm{s}$ & df & Wald & Pr>ChiSq \\
\hline $\begin{array}{l}\text { GI of pre-SBT } \\
\text { Success } \\
\text { Failure }\end{array}$ & $\begin{array}{l}327179 \pm 225318 \\
286800 \pm 147891\end{array}$ & $\mathrm{I}$ & 14.7321 & 0.0001 \\
\hline $\begin{array}{l}\text { ROI2 of SBT } \\
\text { Success } \\
\text { Failure }\end{array}$ & $\begin{array}{l}316615 \pm 521982 \\
237090 \pm 197280\end{array}$ & $\mathrm{I}$ & 9.5871 & 0.0020 \\
\hline
\end{tabular}

Abbreviations: success, weaning success group; failure, weaning failure group; $\mathrm{G}$ of pre-SBT, global impedance on pre-SBT; ROI2 of SBT, ROI2 impedance on SBT.

ROI2. In the present study, the pre-SBT GI predicted the weaning success with a sensitivity of 0.524 , a specificity of 0.818 , a p-value of 0.0496 , and a $95 \%$ confidence interval (CI) of $0.001-0.978$. The sensitivity, specificity, p-value, and 95\% CI for the SBT ROI2 were 1, 0.595, 0.0164 , and 1.010-1.108, respectively (Table 4, Figure 4).

\section{Screening of the Positive Factors by Logistic Regression Analysis During the Two Ventilator Weaning Processes in the Weaning Failure Group EIT Positive Factors}

For the pre-SBT GI and ROI3, SBT ROI4, and post-SBT ROI1, all impedance values during the second weaning were significantly higher than those during the first ventilator weaning, with statistical values of $\mathrm{t}=1.328, \mathrm{p}=0.026, \mathrm{t}=1.334$, $\mathrm{p}=0.015, \mathrm{t}=2.212, \mathrm{p}=0.046, \mathrm{t}=2.504$, and $\mathrm{p}=0.003$, respectively $(\mathrm{p}<0.05)$ (Table 5$)$.

\section{Other Positive Factors}

The pre-SBT $\mathrm{PCO}_{2}$, base excess, and creatinine levels and the post-SBT $\mathrm{pH}$ results all suggested that the second ventilator weaning was better than the first $(p<0.05)$ (Table 5).

\section{Discussion}

Since the ventilator was first adopted by Bjorn Ibsen in 1953 to treat patients with respiratory failure, the question of how to safely conduct ventilator weaning has been an important issue in critical care medicine. Weaning is a gradual process in which patients go from machine support to unassisted breathing and consists of three key steps. First, when the patient's clinical condition permits it, ventilation support is gradually reduced. Second, an SBT is conducted to assess the patient's ability to breathe spontaneously; this phase can comprise either disconnection of the ventilator or the provision of low-level pressure support. Third, the patient is completely disconnected from the ventilator. ${ }^{15}$ Issues arising in any of these steps will result in weaning failure. Currently, the clinically applied evaluation system for ventilator weaning ${ }^{16}$ mainly consists of disease scoring, patient physiological indicators, and ABG value analysis. Therefore, the system has obvious shortcomings since it relies heavily on the subjective judgment of the physician and less on direct indicators of pulmonary ventilation status.

EIT is a valuable tool that allows clinicians to observe the dynamics of pulmonary ventilation in patients in real time at the bedside, and its application in guided studies of ventilator weaning has been reported in recent years. In one such study, ${ }^{17}$ researchers used EIT to record the SBT process in 30 patients and classified the images and data obtained into patterns of gas distribution in the ventral and dorsal lung regions during inspiration. Of the 13 patients with classical pattern ventilation (that is, with a relatively uniform gas pattern in the lungs), only one patient failed to be weaned. In comparison, of the 17 patients with non-
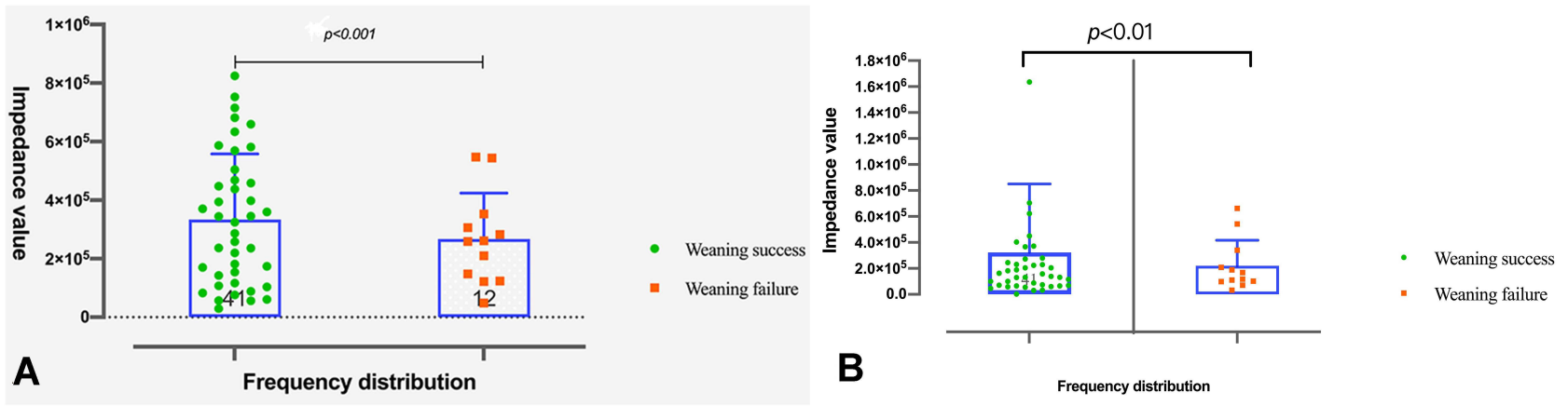

Figure 3 (A) Comparison of pre-SBT EIT global impedance (GI) values between the weaning success and weaning failure groups. (B) Comparison of SBT EIT ROI2 impedance values between the weaning success and weaning failure groups. 
Table 3 Screening of Other Positive Factors During Weaning in the Weaning Success and Weaning Failure Group

\begin{tabular}{|c|c|c|c|c|}
\hline Effect & $\overline{\mathrm{x}} \pm \mathrm{s}$ & df & Wald & Pr>ChiSq \\
\hline $\begin{array}{l}\text { pH on pre-SBT } \\
\text { Success } \\
\text { Failure }\end{array}$ & $\begin{array}{l}7.44 \pm 0.54 \\
7.44 \pm 0.06\end{array}$ & I & 18.7657 & $<0.0001$ \\
\hline $\begin{array}{l}\text { Lac on pre-SBT } \\
\text { Success } \\
\text { Failure }\end{array}$ & $\begin{array}{l}1.74 \pm 2.64 \\
1.55 \pm 1.11\end{array}$ & I & 19.5007 & $<0.0001$ \\
\hline $\begin{array}{l}\mathrm{HCO}_{3}{ }^{-} \text {on pre-SBT } \\
\text { Success } \\
\text { Failure }\end{array}$ & $\begin{array}{l}23.28 \pm 4.75 \\
22.39 \pm 3.48\end{array}$ & I & 30.3414 & $<0.0001$ \\
\hline $\begin{array}{l}\text { Hb on pre-SBT } \\
\quad \text { Success } \\
\text { Failure }\end{array}$ & $\begin{array}{l}95.81 \pm 20.68 \\
92.90 \pm 22.37\end{array}$ & I & 25.1999 & $<0.0001$ \\
\hline $\begin{array}{l}\text { ALT on pre-SBT } \\
\text { Success } \\
\text { Failure }\end{array}$ & $\begin{array}{c}46 \pm 76 \\
22 \pm 9\end{array}$ & I & 26.9516 & $<0.0001$ \\
\hline $\begin{array}{l}\text { pH on post-SBT } \\
\text { Success } \\
\text { Failure }\end{array}$ & $\begin{array}{l}7.40 \pm 0.03 \\
7.39 \pm 0.04\end{array}$ & I & 23.7715 & $<0.0001$ \\
\hline $\begin{array}{l}\mathrm{PCO}_{2} \text { on post-SBT } \\
\text { Success } \\
\text { Failure }\end{array}$ & $\begin{array}{l}38.08 \pm 4.83 \\
35.60 \pm 4.64\end{array}$ & I & 22.7772 & $<0.0001$ \\
\hline
\end{tabular}

Abbreviations: $\mathrm{pH}$ on pre-SBT, $\mathrm{pH}$ of artery blood gas (ABG) on pre-SBT; lac on pre-SBT, lactic acid on pre-SBT; $\mathrm{HCO}_{3}{ }^{-}$on pre-SBT, $\mathrm{HCO}_{3}{ }^{-}$of $\mathrm{ABG}$ on pre-SBT; $\mathrm{Hb}$ on pre-SBT, hemoglobin on pre-SBT; ALT on post-SBT, alanine aminotransferase on pre-SBT; $\mathrm{pH}$ on post-SBT, $\mathrm{pH}$ of $A B G$ on post-SBT; $\mathrm{PCO}{ }_{2}$ on post-SBT, CO 2 pressure of ABG on post-SBT.

Table 4 Specificity and sensitivity of two positive factors related to EIT

\begin{tabular}{|l|c|c|c|c|c|c|}
\hline Effect & AUC & $\mathbf{9 5 \%} \mathbf{C l}$ & P value & CP & Se & Sp \\
\hline GI of pre-SBT & 0.686 & $0.001-0.978$ & 0.0496 & 0.830 & 0.524 & 0.818 \\
ROI2 of SBT & 0.768 & $1.010-1.108$ & 0.0164 & 0.595 & 1 & 0.595 \\
\hline
\end{tabular}

Abbreviations: AUC, area under the curve; CP, cutpoint; Se, sensitivity; Sp, specificity; Gl of pre-SBT, global impedance on pre-SBT; ROI2 of SBT, ROI2 impedance on SBT.

classical pattern ventilation, eight were unsuccessfully weaned. These results indicate that intrapulmonary gas distribution during inspiration is correlated with the outcome of ventilator weaning. In another study, ${ }^{18}$ researchers used EIT to monitor regional pulmonary ventilation in patients with delayed ventilator weaning. EIT recordings were made before and after weaning, and SBT success was adopted as the study's endpoint. The results showed that patients with a global inhomogeneity index of $>40$ were more likely to fail in the SBT. These studies indicate that EIT might have the potential to be added to the clinical evaluation system for ventilator weaning as a new indicator.
Our findings suggest that the pre-SBT GI might be an important indicator of a patient's overall pulmonary ventilation, and it appears that larger values imply higher weaning success rates. This is consistent with data previously collected from healthy adults. Moreover, the high impedance values in ROI2 reflect good ventilation of the pulmonary tissue near the hilum and are also reflected in the significant difference between the weaning success and weaning failure groups in the study, with higher ROI2 levels reflecting higher weaning success rates. Additionally, the receiver operating curve reflects the high sensitivity of ROI2 in predicting the success of ventilator weaning, indicating its potential as a clinical 

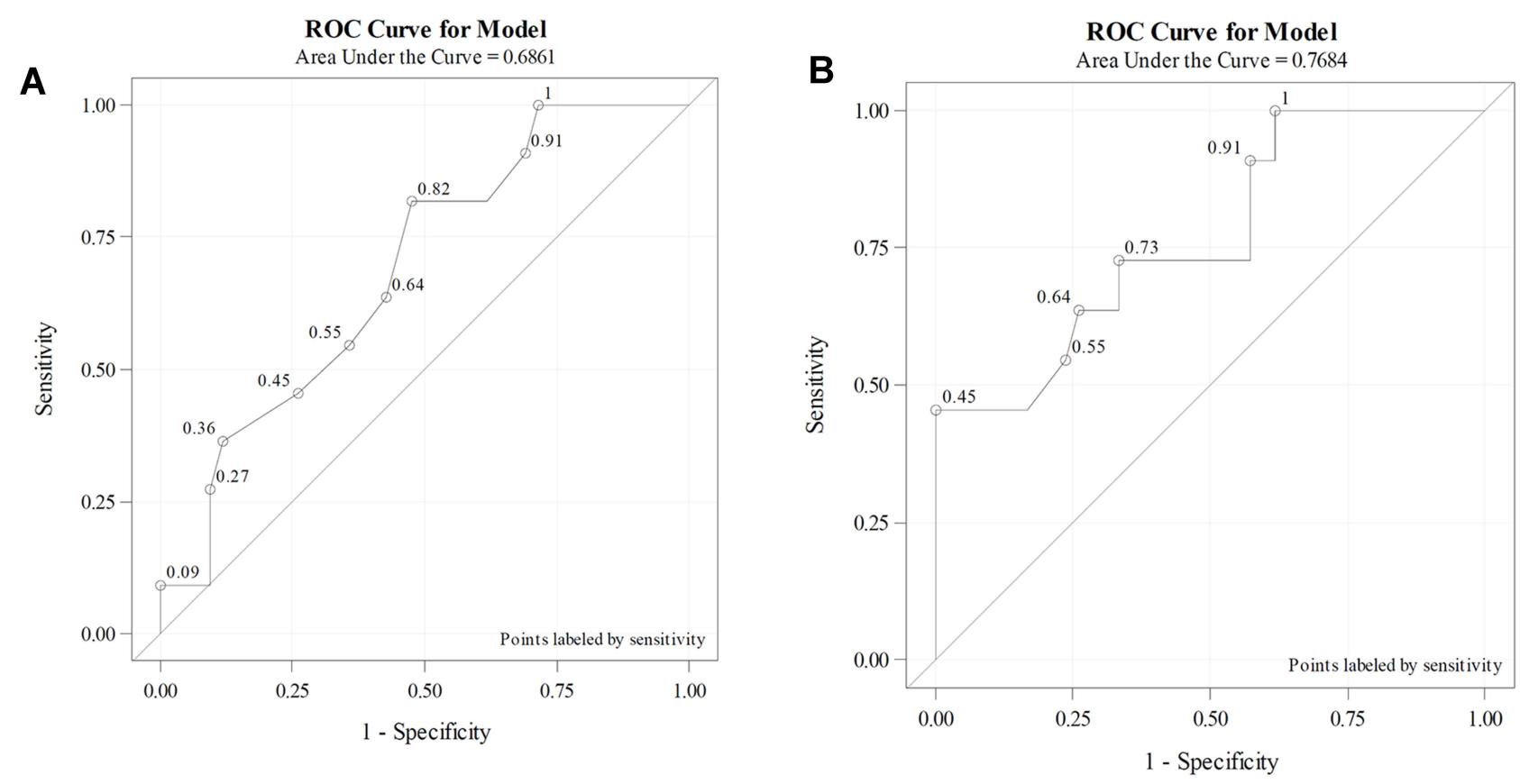

C
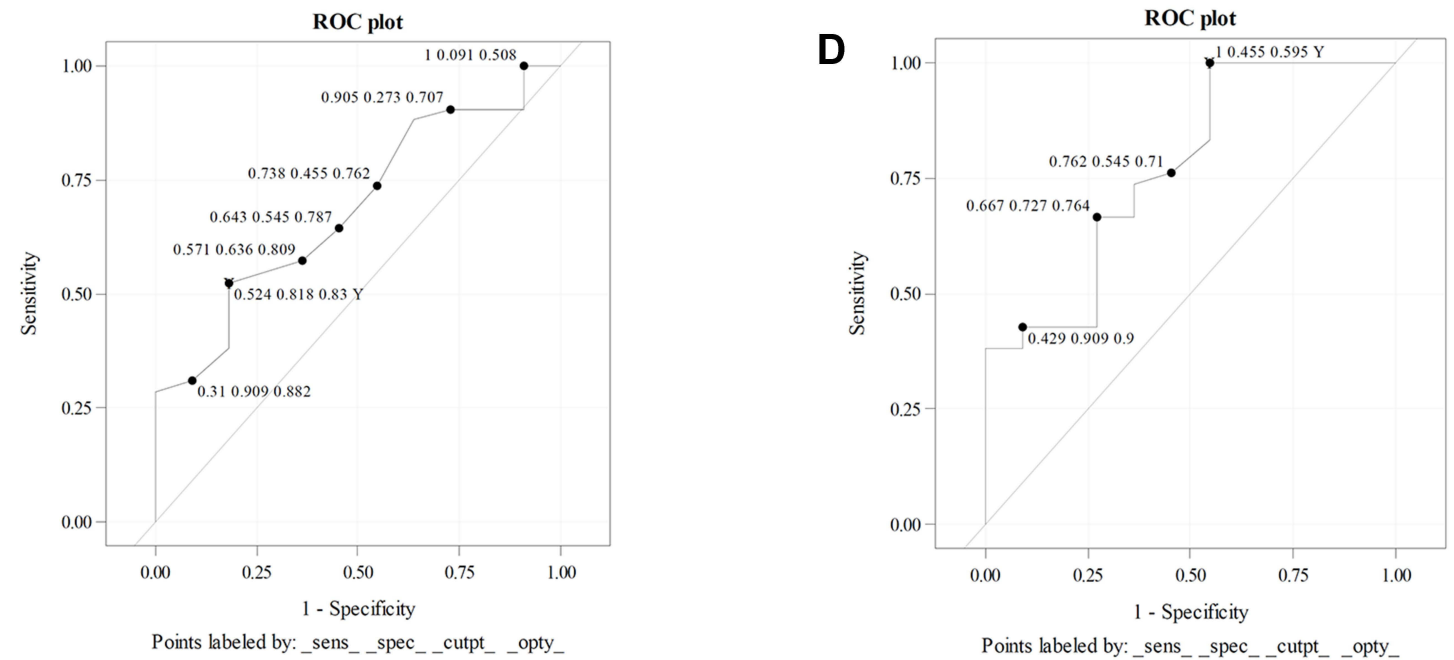

Figure 4 ROC curve for predicting the success of weaning. (A) It shows the AUC of pre-SBT GI is 0.686 . (B) The AUC of ROI2 of SBT is 0.768 . Pre-SBT GI has a higher specificity, and SBT ROI2 is more sensitive. (C) Cut-point value, sensitivity and specificity are $0.83,0.524$, and 0.818 , respectively, in pre-SBT GI. (D) Cut-point value, sensitivity and specificity are I, 0.455 , and 0.595 , respectively, in SBT ROI2.

predictor. While the GI, ROI2, and ROI3 values are not significantly different, the impedance values of ROI1 and ROI4 (reflecting ventilation in the apical and basal pulmonary regions) play a key role. These two regions seem to reflect a patient's ventilation reserve capacity. When the values are compared both before and after the ventilator weaning process in the weaning failure group, it is found that higher levels of ROI1 and ROI4 ventilation imply a greater likelihood of successful weaning. Morphological analysis of EIT images also shows that those patients who were weaned successfully exhibited uniform gas distribution in the lungs and a ventilation status that was mostly consistent with the anatomical features of chest $\mathrm{x}$-ray imaging.

To understand whether EIT is influenced by other factors when used as a weaning indicator, we closely observed the ABG and blood biochemistry results in the weaning success and weaning failure groups, both before and after successful weaning. The $\mathrm{pH}$ and $\mathrm{HCO}_{3}{ }^{-}$in the pre-SBT ABG showed important values during ventilator weaning. When the $\mathrm{pH}$ and $\mathrm{HCO} 3-$ levels in the pre-SBT $\mathrm{ABG}$ were more alkaline, the weaning outcome tended to be more favorable. We theorize that this scenario shows the ability of the pulmonary tissue to balance the internal 
Table 5 Screening of the Influencing Factors of Twice Weaning in the Weaning Failure Group

\begin{tabular}{|c|c|c|c|}
\hline Effect & Mean士SD & $t$ & $p$ \\
\hline \multicolumn{4}{|l|}{ EIT } \\
\hline \multicolumn{4}{|l|}{ ROI3 of pre-SBT } \\
\hline Ist & $93264 \pm 50699$ & 1.328 & 0.026 \\
\hline 2nd & $158918 \pm 12435 \mid$ & & \\
\hline \multicolumn{4}{|l|}{ GI of pre-SBT } \\
\hline Ist & $286800 \pm 147892$ & $\mathrm{I} .334$ & 0.046 \\
\hline 2nd & $385800 \pm 202001$ & & \\
\hline \multicolumn{4}{|l|}{ ROI4 of SBT } \\
\hline Ist & $21085 \pm 15559$ & 2.212 & 0.015 \\
\hline 2nd & $24917 \pm 23302$ & & \\
\hline \multicolumn{4}{|l|}{ ROII of post-SBT } \\
\hline Ist & $43913 \pm 48393$ & 2.504 & 0.003 \\
\hline $2 n d$ & $52209 \pm 55810$ & & \\
\hline \multicolumn{4}{|l|}{ Additional factors } \\
\hline \multicolumn{4}{|l|}{$\mathrm{PCO} 2$ on pre-SBT } \\
\hline Ist & $42.5 \pm 23.1$ & -2.120 & 0.043 \\
\hline 2nd & $39.6 \pm 3.7$ & & \\
\hline \multicolumn{4}{|l|}{ BE on pre-SBT } \\
\hline Ist & $-2.3 \pm 3.8$ & -2.703 & 0.024 \\
\hline 2nd & $-0.3 \pm 2.3$ & & \\
\hline \multicolumn{4}{|l|}{$\mathrm{Cr}$ on pre-SBT } \\
\hline Ist & $105 \pm 100$ & 2.343 & 0.044 \\
\hline 2nd & $64 \pm 26$ & & \\
\hline \multicolumn{4}{|l|}{$\mathrm{pH}$ on post-SBT } \\
\hline Ist & $7.39 \pm 0.1$ & -2.447 & 0.037 \\
\hline 2nd & $7.40 \pm 0.0$ & & \\
\hline
\end{tabular}

environment during the recovery phase of the disease, ie, compensatory activity for the acid-base imbalance triggered by the accumulation of acidic metabolites in the body. These findings were also reflected in the pre-SBT ALT levels and the post-SBT $\mathrm{pH}$ and $\mathrm{PCO}_{2}$.

\section{Conclusions}

As mentioned above, we believe that the existing evaluation system for ventilator weaning should be improved by the introduction of new indicators. In the present system, the indicators for ventilator weaning that reflect pulmonary ventilation are indirect (eg, ABG values and rapid shallow breathing indices). In this study, we demonstrate the better sensitivity and specificity of EIT as a tool for the direct observation of pulmonary ventilation status, especially using pre-SBT GI and SBT ROI2 as predictors. We assert that, by using these methods, clinicians could be aided to make more accurate judgments. An additional cohort study that explores the use of EIT versus the existing evaluation system would help provide more robust supporting evidence for the use of EIT in ventilator weaning.

\section{Ethics Approval and Consent to Participate}

This study was conducted with approval from the Ethics Committee of Beijing Luhe Hospital, Capital Medical University, approval number 2018LH-KS-015. This study was conducted in accordance with the declaration of Helsinki. Written informed consent was obtained from all participants.

\section{Funding}

This study was funded by Science and Technology Committee of Tongzhou District, Beijing City. (Grant Number: KJ2018CX009-20). The funding body had no role in the design of the study and collection, analysis, and interpretation of data and in writing the manuscript.

\section{Disclosure}

The authors report no conflicts of interest in this work.

\section{References}

1. Sellares J, Ferrer M, Cano E, et al. Predictors of prolonged weaning and survival during ventilator weaning in a respiratory ICU. Intensive Care Med. 2011;37(5):775-784.

2. Nemer SN, Barbas CS. Predictive parameters for weaning from mechanical ventilation. J Bras Pneumol. 2011;37(5):669-679. doi:10.1590/S1806-37132011000500016

3. Dehghani A, Abdeyazdan G, Davaridolatabadi E, et al. An overview of the predictor standard tools for patient weaning from mechanical ventilation. Electron Physician. 2016;8(2):1955-1963. doi:10.19082/1955

4. Blackwood B, Burns KEA, Cardwell CR, et al. Protocolized versus non-protocolized weaning for reducing the duration of mechanical ventilation in critically ill adult patients. Cochrane Database Syst Rev. 2014;2014(11):CD006904.

5. Roberts KJ. 2018 year in review: adult invasive mechanical ventilation. Respir Care. 2019;64(5):604-609. doi:10.4187/ respcare.06927

6. Burns KEA, Rizvi L, Cook DJ, et al. Ventilator weaning and discontinuation practices for critically ill patients. JAMA. 2021;25 (12):1173-1184. doi:10.1001/jama.2021.2384

7. Dias OM, Costa EL, Pereira DA, et al. Tracheobronchomalacia in a patient on invasive mechanical ventilation: the role of electrical impedance tomography in its detection and positive end-expiratory pressure titration. J Bras Pneumol. 2015;41(2):203-205. doi:10.1590/ S1806-37132015000004410

8. Frerichs I, Amato MB, van Kaam AH, et al. Chest electrical impedance tomography examination, data analysis, terminology, clinical use and recommendations: consensus statement of the translational EIT development study group. Thorax. 2017;72(1):83-93. doi:10.1136/thoraxjnl-2016-208357 
9. Bayford R, Halter RJ. Focus on advances in electrical impedance tomography. Physiol Meas. 2018;39(9):090301. doi:10.1088/13616579/aad93e

10. Nishimura M. Electrical impedance tomography: the promise of noninvasive lung images at the bedside. Respir Care. 2020;65 (3):402-403. doi: $10.4187 /$ respcare.07716

11. Becher TH, Bui S, Zick G, et al. Assessment of respiratory system compliance with electrical impedance tomography using a positive end-expiratory pressure wave maneuver during pressure support ventilation: a pilot clinical study. Crit Care. 2014;18(6):679-690. doi:10.1186/s13054-014-0679-6

12. Blankman P, Shono A, Hermans BJ, et al. Detection of optimal PEEP for equal distribution of tidal volume by volumetric capnography and electrical impedance tomography during decreasing levels of PEEP in post cardiac-surgery patients. Br J Anaesth. 2016;116(6):862-869. doi:10.1093/bja/aew116

13. Cinnella G, Grasso S, Raimondo P, et al. Physiological effects of the open lung approach in patients with early, mild, diffuse acute respiratory distress syndrome: an Electrical Impedance Tomography Study. Anesthesiology. 2015;123(5):1113-1121. doi:10.1097/ALN.0000000 000000862
14. Girard TD, Alhazzani Wakes W, Kress JP, et al. An Official American Thoracic Society/American College of Chest Physicians Clinical Practice Guideline: liberation from mechanical ventilation in critically ill adults. rehabilitation protocols, ventilator liberation protocols, and cuff leak tests. Am J Respir Crit Care Med. 2017;195 (1):120-133. doi:10.1164/rccm.201610-2075ST

15. Vetrugno L, Guadagnin GM, Brussa A, et al. Mechanical ventilation weaning issues can be counted on the fingers of just one hand: part 1 . Ultrasound J. 2020;12(1):9-18. doi:10.1186/s13089-020-00161-y

16. Baptistella AR, Sarmento FJ, da Silva KR, et al. Predictive factors of weaning from mechanical ventilation and extubation outcome: a systematic review. J Crit Care. 2018;48:56-62. doi:10.1016/j. jcrc.2018.08.023

17. Zhao Z, Peng S-Y, Chang M-Y, et al. Spontaneous breathing trials after prolonged mechanical ventilation monitored by electrical impedance tomography: an observational study. Acta Anaesthesiol Scand. 2017;61(9):1166-1175. doi:10.1111/aas.12959

18. Bickenbach J, Czaplik M, Polier M, et al. Electrical impedance tomography for predicting failure of spontaneous breathing trials in patients with prolonged weaning. Crit Care. 2017;21(1):177. doi:10.1186/s13054-017-1758-2
International Journal of General Medicine

\section{Publish your work in this journal}

The International Journal of General Medicine is an international, peer-reviewed open-access journal that focuses on general and internal medicine, pathogenesis, epidemiology, diagnosis, monitoring and treatment protocols. The journal is characterized by the rapid reporting of reviews, original research and clinical studies
Dovepress

across all disease areas. The manuscript management system is completely online and includes a very quick and fair peer-review system, which is all easy to use. Visit http://www.dovepress.com/ testimonials.php to read real quotes from published authors. 